\title{
Dhaka stress scale-adolescent: A scale for assessing psychosocial stressors among adolescents
}

\author{
Mohammad S. I. Mullick, Sultana Algin, Monirul Islam, Adrian Phillipson, Jhunu S. Nahar, \\ Nahid Mahjabin Morshed, Hafizur Rahman Chowdhury and Selina Fatema Binte Shahid
}

\section{Article Info \\ Department of Psychiatry, Faculty of Medicine, Bangabandhu Sheikh Mujib Medical University, Shahbag, Dhaka, Bangladesh (MSIM, SA, MI, JSN, NMM, HRC, SFBS); Rotherham Doncaster and South Humber Foundation Trust, Don- caster, UK (AP). \\ For Correspondence: \\ Mohammad SI Mullick \\ msimullick@gmail.com \\ Received: \\ Accepted: \\ Available Online: \\ 10 September 2019 2 December 2019 23 December 2019 \\ ISSN: 2224-7750 (Online) \\ 2074-2908 (Print) \\ DOI: 10.3329/bsmmuj.v12i4.44273}

Keywords: Adolescent; Dhaka stres scale; Psychosocial stressor

\section{Cite this article:}

Mullick MSI, Algin S, Islam M, Phillipson

A, Nahar JS, Morshed NM, Chowdhury $H R$, Shahid SFB. Dhaka stress scaleadolescent: A scale for assessing psychosocial stressors among adolescents. Bangabandhu Sheikh Mujib Med Univ J. 2019; 12: 167-176.

\section{Copyright:}

The copyright of this article is retained by the author(s) [Atribution CC-By 4.0]

Available at:

www.banglajol.info

A Journal of Bangabandhu Sheikh Mujib Medical University, Dhaka, Bangladesh

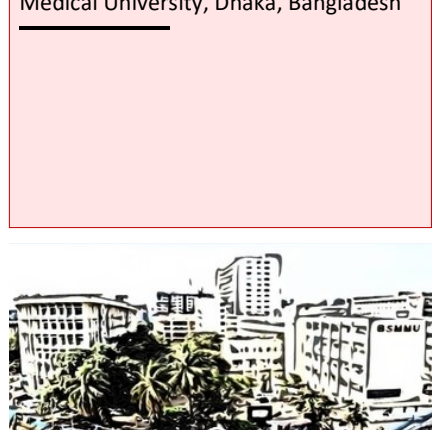

\section{Abstract}

This study was aimed to produce a culturally validated scale to determine the presence of stressful life events among adolescents in Bangladesh, and formulate the relative life change units for each event. The study used qualitative research, including a focus group and questionnaire, and quantitative analysis in the validation process. Researchers first developed a provisional stress scale that was translated in Bangla through a translation exercise. Using an open-ended question along with this provisional scale on a school sample of 449 (228 rated on imagination and 221 on actual experience) adolescents, researchers developed Dhaka stress scale-adolescent with 56 items and predictive interpretation of the overall score was made. Content validity was found excellent as item level content validity index was around 1 and the scale level validity index was 0.93 . The correlation coefficient was 0.72 between this scale and adolescent life events stress scale. For reliability, Cronbach's alpha values were ranged from 0.83 to 0.97 . The scale is simple to administer to assess stress in adolescents and usable in both clinical and research settings.

\section{Introduction}

Adolescence is often associated with profound changes in multiple contexts concurrently give rise to an increased load of potential stressors. $\underline{1-2}$ The implication of stress for children and adolescents can be far-reaching, depending on its level, persistency and vulnerability in term of developmental factors and low resiliency.

The relation of stressful life events with wide range of symptoms and disorders has been well documented in adults. $\frac{3-10}{10}$ Studies of this relation in children and adolescents have also demonstrated that stressors can cause negative physical, mental and cognitive outcomes for them..11 Stressors are associated with later development of internalizing as well as externalizing problems, $\underline{12,13}$ anxiety, depression, psychosis, impaired memory and language skills, $\underline{14-16}$ stress related problems, $17-19$ and more psychiatric problems overall. Stressors also cause weakened immune system, diverse physical disorders like psychosomatic disorders, heart disease, obesity diabetes, and asthma.20-21 In considering this relationship researchers identified several vulnerability factors, such as genetic predisposition, difficult temperament, tendency to blame negative events on themselves, social, economic and environmental factors. $22-24$

In Bangladesh, significantly higher rate of stressors both in frequency and severity was found in adolescents with self-harm, $\underline{25}$ somatoform disorders, $\underline{26,27}$ school refusal, $\underline{28}$ conversion disorder, 29-31 anxiety and stress related disorders,, 32 internalizing and externalizing problems, $\underline{33}$ juvenile idiopathic arthritis and chronic physical disorders. 34 In these studies, assessments of stressful life events were carried out using relevant section of DSM-III-R, ICD-10, Social Readjustment Rating Scale (SRRS) $\underline{35}$ and other foreign tools. $\underline{36}$

Studies have attempted to evaluate the cultural validity of stressful life events scales among adolescents or children.37-42 Several authors have attempted to use the SRRS and its technique, $\underline{43,45}$ and to validate this scale culturally. $\underline{46}$ Other studies have used focus groups and surveys. 27 Perhaps the most relevant attempts of SRRS cultural validation for adolescent stress assessment are Life Event Record $\underline{48}$ and Adolescent Life Events Stress Scale.49 These scales were found unsuitable in the context of Bangladesh as experienced and judged by the researchers and thereby could not assess stress more perfectly.25-34 With the same reasons, researchers of the present study initially developed a new scale named Dhaka stress scale- Adults (DSS-A) to measure stressful life events among adults in Bangladesh. $\underline{50}$ This research was conducted as a continuum of fulfilling the same requirement for adolescents in Bangladesh. The objectives of the study were to produce a new culturally validated stress scale for assess- 
ing stressful life events in Bangladeshi adolescents and to estimate the mean stress score for each stressor experienced by adolescent population in the past year.

\section{Materials and Methods \\ Design}

This mixed methodological i.e. qualitative and quantitative type of study was conducted from July 2016 to June 2017. For development and cultural validation of an adolescent stressful life event scale with life change units, the study was broken down into a two-phase process. Phase one was cultural validation that all the stressful life events on the scale, potentially stressful to the population to be surveyed and no culturally relevant life events had been excluded. Phase two was validation of the mean stress scores in terms of life change units for each event on the scale. As there was no clearly defined gold standard to validate each event, a multi-step validation for each phase was utilized in this research with mixed methodology for each phase.

\section{Scale formulation}

Initial stress items of Dhaka stress scale-Adolescent (DSS-Ad) were selected from the life event recordLER, $\underline{48}$ Adolescent life events stress scale-ALES, $\underline{\underline{9}}$ all the relevant research on psychosocial stressors in Bangladesh and extensive clinical experiences of researchers to construct a culturally relevant primary list of stressful life events.

\section{Focus group discussion}

A focus group was formed involving 10 mixed mental health professionals (five women and five men) familiar with working on those with mental distress and life stressors among adolescents. They were of different professional backgrounds and experiences: five psychiatrists, three clinical psychologists and two psychologists. In total five sessions of focus group discussions were held in July and August, 2016. Each session was for $90 \mathrm{~min}$. It was an adequate length for a group of ten professionals to provide saturation for the research topic. The group was moderated by the primary investigator, with a supplementary researcher. The group discussion was took place in English as primary language with Bangla used where appropriate. The focus group was participant lead, with the moderator ensuring that the focus remained on the primary research questions. The discussions were audio-taped that agreed by participants, and transcribed verbatim for analysis. The recordings were securely stored until transcribed and then destroyed. The transcription did not contain information that could allow individuals to be linked to specific statements. Confidentiality was strictly pre- served. The preliminary list of stressful life events was available for the focus group to guide discussion. Through the focus group discussions, the researchers wanted to make sure that the items chosen were relevant with regard to the developmental period and also gathered information about possible stressful life events not relevant to Bangladeshi adolescents and identify additional stressful life events needed to add to generate provisional DSS-Ad.

The moderator initiated the discussion and asked the group members to give their input one by one. Moderator recited all the stressful life events included in the primary list then asked to the group members to identify the possible events not relevant to Bangladeshi adolescents. Most of the items of the provisional list were agreed by members. Some of them were discarded because the members argued that they were not culturally appropriate. The members explored some new events appropriate for Bangladeshi culture and were not in the list. In this way at the last sessions of focus group discussion, data were transcribed and researchers got some culturally relevant stressors which added and some stressors were discarded from the primary list. Following stressors were discarded as it had been agreed that these were either not relevant to adolescents in Bangladesh or incorporated and merged into other suitable stressor items. From LER, discarded items were: increase in number of arguments with parents, decrease in number of arguments with parents, beginning another school year, suspension from school, fathering of unwanted pregnancy, pregnancy of unwed sister, discovery of being adopted child, not making an extracurricular activity, beginning to date, change of parents' financial status, accepted at college of choice, being a senior in high school, and addition of third adult to family. From ALESS, discarded items were: change in eating habits, change in social activities, change in sleeping habits, change in living conditions, change in health of family member, death of pet, change in financial status of parents, serious argument with teacher, and marriage of an emotionally closed sibling. Following stressors were added as it was agreed that these were relevant to adolescents in Bangladesh: sexual harassment, excessive parental pressure for academic performance, increase in number of arguments with parents, harsh behavior of teacher, downgrading financial status of parents, dropped out from study, lack of boy/girl friend, excessive abuse of internet or mobile, lack of recreational facilities, failure to get admission in a school or college of choice, and change in personal habit (sleeping, eating etc.), Culturally relevant stressful life events for adolescents generated by the focus group discussion contributed a lot to the development of a culturally validated screening tool and thus 56 itemed provisional DSS-Ad was prepared. 


\section{Translation exercise}

Provisional DSS-Ad then translated and back translated to Bangla and English by four psychiatrists and psychologists having competency on both Bangla and English and four language experts according to the guideline proposed by Beaton et al. (2006). 51 After random ranking of items, this provisional Bangla version of DSS-Ad with 56 items was pretested to resolve discrepancies and applied for data collection.

\section{Data acquisition}

This part of the study was conducted in a school of Dhaka city. The school was located in a moderately prosperous urban residential area where most families were of mainly middle and partly low and high socioeconomic status and almost all adolescents of targeted age group attended school. Both boys and girls were available for recruitment as it was coeducational school and had up to Grade-12 educational facilities. It was chosen after informal local consultation at least as one of the representative schools of that area. Students between 12-18 years of either sex were recruited through class register by simple random technique. Socio-demographic data of the subjects were collected by using a structured questionnaire. A total of 449 students, consisting of both boys $(n=199$ and girls $(n=250)$ of different socio-demographic strata were enrolled. Of the sample, 228 subjects were asked to rate the imaginary stress that they have experienced each event of provisional DSS-Ad though they had not really experienced that item in a Likert scale ranging from 1 to 5 where 1 represented not at all stress, 2, 3, 4 and 5 represented a little stress, a mild amount of stress, a moderate amount of stress and a great deal of stress respectively. Another 221 subjects were asked to rate only those events of provisional DSSAd which they had actually experienced in the last year in the same way. In the original version of the scale, mean stress scores were presented after multiplying of these range of severities with 20 . Every subject was requested to add additional events in the blank space which were not in the scale. Several responses received from both imagined and experienced groups. These were considered and evaluated carefully and were discarded as the items were either included in one of the items already existing in the provisional DSS-Ad or were chronic/ongoing in nature or were description of a state or too vague to be included. According to statistical loading, mean score of 25 or above was considered as cut-off to include a stressful life event as an item of this scale.

\section{Scale validation}

The two principle psychometric properties namely reliability and validity for this scale were measured. A 6-membered expert committee (psychiatrists having competency on both Bangla and English) reviewed the DSS-Ad. They provided their valuable opinion about the face validity. Content validity was assessed by the item-level content validity index (I-CVI) and the scale-level content validity index (S-CVI). Content validity indices were assessed by three psychiatrists. Each expert rated each item either 1 (not relevant), 2 (somewhat relevant), 3 (quite relevant) or 4 (highly relevant). Then, for each item, the I-CVI was computed as the number of experts giving a rating of either 3 or 4 (thus dichotomizing the ordinal scale into relevant and not relevant), divided by the total number of experts. The S-CVI was measured by averaging calculation method (S-CVI/Ave), i.e. by the average of the ICVIs for all items on the scale. The scale was judged to have good content validity if the I-CVI $=1$ for each item and the S-CVI/Ave $\leq 0.9$, as recommended by Polit and Beck (2006). .52 Internal consistency was assessed by Cronbach's alpha. $\underline{53}$ Instrument that are used clinically should have coefficient alpha of 0.80 or higher often closer to 0.90 . Cronbach's alpha should lies between 0 and 1 . Values are usually expected to be above 0.7 and below 0.9 . Alpha below 0.7 broadly indicates poor internal consistency and above 0.9 suggests that the items are very similar and perhaps fewer items could be used to obtain the same overall information. $\underline{.4}$

\section{Interpretation}

For the DSS-Ad, general guideline of the interpretation of score was made to assess the individuals with the level of stress. According to the total score on 3-point scale - mild, moderate and severe levels were categorized. As follows: score 150 or less suggesting mild level of stress, score 151 to 300 suggesting moderate level of stress and score 301 or more suggesting severe level of stress.

\section{Data analysis}

Data analysis was performed by statistical package for social science (SPSS), version-20. Statistical analysis was done using frequencies and percenttages and by applying Spearman's rank correlation test, Intra-class correlation coefficient and t-test. All tests were two tailed and $\mathrm{p}<0.05$ was considered statistically significant.

\section{Results \\ Sample characteristics}

Of the sample of 449 adolescents, 199 were boys and 250 were girls and boy: girl ratio was 1:1.3. Their age ranged from 10 to 18 years with a mean of 14.2 \pm 3.1 years. Most of the subjects $(25.8 \%)$ were in Grade- 6 followed by Grade-8 (22.7\%) and lowest $(2.9 \%)$ were in Grade-12 level of education. Among the subjects, 422 were from urban and 27 were from rural background (Table I). Majority of the subjects were Muslims (93\%) followed by Hindus (4.9\%) and 


\begin{tabular}{|c|c|c|c|}
\hline \multicolumn{4}{|c|}{ Table I } \\
\hline \multicolumn{4}{|c|}{ Characteristics of sample } \\
\hline Characteristics & $\mathrm{n}=449$ & $\begin{array}{l}\text { Number of } \\
\text { events in last } \\
\text { year }\end{array}$ & $\begin{array}{c}\text { Mean stress } \\
\text { score }\end{array}$ \\
\hline \multicolumn{4}{|l|}{ Age (Years) } \\
\hline 10 & 5 & & 27 \\
\hline 11 & 47 & & 46 \\
\hline 12 & 69 & & 35 \\
\hline 13 & 69 & & 53 \\
\hline 14 & 81 & & 50 \\
\hline 15 & 64 & & 54 \\
\hline 16 & 47 & & 48 \\
\hline 17 & 47 & & 63 \\
\hline 18 & 20 & & 50 \\
\hline \multicolumn{4}{|l|}{ Sex } \\
\hline Boy & 199 & 2.9 & 40 \\
\hline Girl & 250 & 3.1 & 56 \\
\hline \multicolumn{4}{|l|}{ Level of education } \\
\hline Grade-6 & 116 & 3.1 & 37 \\
\hline Grade-7 & 59 & 2.2 & 46 \\
\hline Grade-8 & 102 & 3.5 & 60 \\
\hline Grade-9 & 61 & 3.6 & 48 \\
\hline Grade-10 & 48 & 4.1 & 48 \\
\hline Grade-11 & 50 & 3.5 & 67 \\
\hline Grade -12 & 13 & 4.2 & 30 \\
\hline \multicolumn{4}{|c|}{ Desirable vs. undesirable } \\
\hline Desirable & 18 & & 48 \\
\hline Undesirable & 38 & & 51 \\
\hline \multicolumn{4}{|c|}{ Experienced vs. imaginary } \\
\hline Experienced & 228 & & 17 \\
\hline Imaginary & 221 & & 82 \\
\hline \multicolumn{4}{|c|}{ Controlled vs. uncontrolled } \\
\hline Controlled & 3 & & 48 \\
\hline Uncontrolled & 41 & & 48 \\
\hline Combined & 12 & & 53 \\
\hline \multicolumn{4}{|c|}{ Personal vs. impersonal } \\
\hline Personal & 33 & & 51 \\
\hline Impersonal & 23 & & 47 \\
\hline
\end{tabular}

the rest were Christens and Buddhists with $6 \%$ and $0.7 \%$ respectively. In terms of family type, $86 \%$ came from nuclear families and the rest $14 \%$ were from joint families.

\section{Life events experienced in last year}

The mean of total numbers of life events experienced by the subjects was 3.5 with a range of 2.2-4.2. Of the cases, Grade- 12 subjects experienced highest numbers of life events with a mean of 4.2. It was 4.1, 3.6 and 3.5 in the Grade-10, 9 and 8 groups respectively. This result revealed that an individual experienced an average of three and half stressful life events in a year without having any psychiatric disorder. Girls experienced slightly more life events (3.1) than boys (2.9) with a ratio of 1: 1.3.

\section{Mean stress score by different characteristics}

Mean stress scores according to different characteristics is also shown in Table I. Highest mean score was found 63 among 17-year old subjects. That was lowest among 10 years old with the mean score of 27. Mean stress score among the boys was 40 and that was higher among girls which was 56. According to the educational level, highest mean score was found among Grade-11 subjects with the mean of 67 and the lowest was among Grade- 6 subjects with the mean of 37 . Undesirable stressful life events were higher than desirable life events with the mean score of 51 and 48 respectively. Further, mean stress score was higher among the imaginary group which was 82 than experienced group which was 17 . Mean stress score was 53 among the group with combined controlled and uncontrolled life events than the groups with either controlled or uncontrolled life events with the mean score of 48 for each. Mean stress score of personal life events was 51 which was slightly higher than impersonal events with the mean score 47.

\section{Individual stress score}

DSS-Ad contained 56 stressful life events (Table II). Bangla version was also prepared with the same contents. The items in the scale are quantified as mean stress scores. The death of a parent was perceived as most stressful life event with a mean stress score of 94 and outstanding achievement of a sibling was ranked as least stressful life event with a mean stress score of 27. The items were ranked according to decreased in severity of perceived stress. In case of same mean stress score, researchers considered the fraction of that score.

Mean stress score according to area of stressful life events

The individual events were grouped into nine types according to social area of activities. Again, these areas were ranked according to decreased in severity of perceived stress. Of the nine types, other interpersonal (number of life events was 4) ranked as most stressful area with mean stress score of 57 . Educational area (number of life events was 13) was the next with mean stress score of 55 . The mean stress score of others seven areas were: Familial (number of life events was 18) 50, conjugal (number of life events was 3) 50. Living circumstances (number of life events was 3) 47. Physical illness/ injury (number of life events was 3) 47 , Financial 
Table II

Mean ranked stress scores of each item of stressful life events

\begin{tabular}{|c|c|c|c|c|c|}
\hline $\begin{array}{l}\text { Rank } \\
\text { No. }\end{array}$ & Stressful life events & $\begin{array}{l}\text { Mean } \\
\text { stress } \\
\text { score }\end{array}$ & $\begin{array}{l}\text { Rank } \\
\text { No. }\end{array}$ & Stressful life events & $\begin{array}{l}\text { Mean } \\
\text { stress } \\
\text { score }\end{array}$ \\
\hline 1 & Death of a parent & 94 & 29 & Loss of academic year & 48 \\
\hline 2 & $\begin{array}{l}\text { Excessive parental pressure for academic per- } \\
\text { formance }\end{array}$ & 88 & 30 & Dropped out from study & 47 \\
\hline 3 & Fall in love & 84 & 31 & Downgrading financial status of the family & 47 \\
\hline 4 & Increased academic workload & 78 & 32 & Having a visible congenital deformity & 47 \\
\hline 5 & Lower grade in examination than expected & 71 & 33 & Unwanted pregnancy & 47 \\
\hline 6 & Failed in examination & 68 & 34 & Becoming involved with drug addiction & 47 \\
\hline 7 & Upcoming examination & 66 & 35 & Becoming pregnant & 46 \\
\hline 8 & Divorce of parents & 65 & 36 & Mother beginning to work & 46 \\
\hline 9 & Broke up with boy friend or girl friend & 63 & 37 & Extramarital relationship of parents & 46 \\
\hline 10 & Excessive abuse of internet or mobile & 61 & 38 & Death of a close friend & 46 \\
\hline 11 & Having step parent & 61 & 39 & $\begin{array}{l}\text { Serious illness requiring hospitalization of a } \\
\text { parent }\end{array}$ & 45 \\
\hline 12 & Sexual harassment & 59 & 40 & Imprisonment or jail sentence of a parent & 44 \\
\hline 13 & $\begin{array}{l}\text { Failure to get admission in a school or college } \\
\text { of choice }\end{array}$ & 59 & 41 & Harsh behavior of teacher & 44 \\
\hline 14 & Parental separation & 57 & 42 & Loss of job of a parent & 43 \\
\hline 15 & Death of a close family member & 57 & 43 & Lack of recreational facilities & 43 \\
\hline 16 & Serious illness requiring hospitalization of self & 55 & 44 & Brother or sister leaving home & 40 \\
\hline 17 & $\begin{array}{l}\text { Serious illness requiring hospitalization of a } \\
\text { sibling }\end{array}$ & 54 & 45 & Acquiring a visible deformity & 40 \\
\hline 18 & Discord with parents & 53 & 46 & $\begin{array}{l}\text { Increase absence of a parent from home for changing } \\
\text { profession }\end{array}$ & 35 \\
\hline 19 & Trouble with bully & 52 & 47 & Change of school & 34 \\
\hline 20 & Beginning or ending of school & 52 & 48 & Outstanding personal achievement & 33 \\
\hline 21 & Sex problem & 50 & 49 & Change of academic subjects or branch & 33 \\
\hline 22 & Parental discord & 50 & 50 & Theft of personal belongings & 31 \\
\hline 23 & Marriage & 49 & 51 & Change in personal habit (sleeping, eating etc.) & 31 \\
\hline 24 & Birth of a sibling & 49 & 52 & Lack of school attendance & 30 \\
\hline 25 & Discord with peer & 49 & 53 & Change in family role and responsibilities & 30 \\
\hline 26 & Serious illness of a family member & 48 & 54 & Relocation of family & 28 \\
\hline 27 & Lack of boy or girl friend & 48 & 55 & Minor violation of law & 28 \\
\hline 28 & Discord with sibling & 48 & 56 & Outstanding achievement of a sibling & 27 \\
\hline
\end{tabular}

(number of life events was 1) 43. Legal (number of life events was 2) 36 .

\section{Severity of stress}

The distribution of the subjects reveals that mild level of stress was found among $60 \%$ of the subjects. Subjects with moderate stress level were $28 \%$ and the rest $16 \%$ subjects were at severe level.

\section{Validity and reliability}

Result shows that all items had good content validity except 6 items. Scale level content validity index (S-CVI) was measured by averaging the ICVIs of all items and the value was 0.93 . Concurrent validity was assessed between ALESS and DSS-Ad. Table III shows the correlation between these two scales. It depicts that the correlation coefficient was 0.723 which reflected very strong positive correlation between two scales. Moreover, correlation was statistically significant as $\mathrm{p}$ value was $<0.05$.

For reliability, Cronbach's alphas were calculated from various permutations of the DSS-Ad. Internal consistency for the 56 items of DSS-Ad was 0.89 . DSS-Ad was explained by two-factor model. The first factor consisted of 32 items with salient loadings ( $p>0.40)$. The second factor consisted of 24 items. No item had salient loading on more than 


\begin{tabular}{|cccc|}
\hline \multicolumn{3}{|c|}{ Table III } \\
\hline \multicolumn{3}{|c|}{ Correlations } \\
\hline \multicolumn{4}{|c|}{ Concurrent validity-correlation of DSS-Ad and ALESS } \\
\hline \multirow{3}{*}{ DSS_Ad } & DSS-Ad & ALESS \\
& Pearson correlation & 1 & $0.723^{\mathrm{a}}$ \\
& Sig. (2-tailed) & & 0.028 \\
ALESS & $\mathrm{N}$ & 9 & 9 \\
& Pearson correlation & $0.723^{\mathrm{a}}$ & 1 \\
& Sig. (2-tailed) & 0.028 & 9 \\
aCorrelation is significant at the 0.05 level (2-tailed) & 9 & \\
\hline
\end{tabular}

one factor and there were 6 items that failed to load on either factor. Cronbach's alpha according to the area of stressors of different areas of stressors is presented in the Table IV. Cronbach's alpha of stressors was ranged from 0.83 to 0.97 . All social areas were moderately to strongly correlated with each other. The term communality for a given variable can be interpreted as the proportion of variation in that variable explained by the two factors. The term communality for a given variable can be interpreted as the proportion of variation in that variable explained by the two factors. For example, communality $=0.67$ implies that $67 \%$ of the variation. Communality of 56 items was ranged from $0.36-0.85$. Communality of 6 items was slightly below the expected level.

\section{Discussion}

Several authors have highlighted the importance of health research in South Asia, $\underline{55}$ citing large population numbers and health policies that are often unsupported by research. Research quantity is increasing in South Asia including Bangladesh, and there is a need to develop culturally validated research tools to support this. This study has produced a culturally appropriate scale for measuring stressful life events among adolescent population in Bangladesh for both clinical and research use that is equally applicable in Bangladeshi communities in other countries.

The DSS-Ad is designed to identify stressful life events experienced by normal adolescent population of Bangladesh in the past year and measuring the types, frequency and quantity of stressors but can be used for any time frame to life long. It has both Bangla and English versions. It is a selfreported scale applicable for either sex of 10-18 year olds. It comprises 56 items that are rated on given mean stress score and takes $15-20 \mathrm{~min}$. The items are rated on given mean stress score on the left of each event. If the adolescent experienced that event in the past year, is written that number on the blank space to the right. If any event happened more than
Table IV

Cronbach's alpha according to area of stressful life events

\begin{tabular}{|lc|}
\hline Area & Cronbach's alpha \\
\hline Conjugal & 0.84 \\
Family & 0.97 \\
Living circumstances & 0.83 \\
Other interpersonal & 0.86 \\
Educational & 0.87 \\
Legal & 0.82 \\
Physical illness/injury & 0.90 \\
Others & 0.83 \\
\hline
\end{tabular}

once, is multiplied for each occurrence. The simple sum of all items rating constitutes the total score. On the basis of the other valid stress scales and research reports, researchers have extrapolated the general guidelines of interpretations of the overall scores of DSS-Ad. Thus it can screen the potential risk population. However, this interpretation is not absolute because of the large differences in individual's ability to cope and particular reaction to stress, and because of the lack criterion referred validity tasted on large healthy as well as sick adolescent population. Therefore, the interpretation should be considered as probable and approximate.

In the present study, 56 stressful life events of diverse nature were included as items of DSS-Ad. Higher ranking top 10 stressful life events in descending order were: Death of a parent, excessive parental pressure for academic performance, fall in love, increased academic workload, lower grade in examination than expected, failed in examination, upcoming examination, divorce of parents, broke up with boy friend or girl friend, excessive abuse of internet or mobile. These stressful life events are of academic, familial and interpersonal in nature. Education, and family and interpersonal relationship were found higher among normative as well as sick young population are the prime concerned areas because life events related two these areas were reported to have higher causal relationship with psychiatric as well as other medical disorders among adolscents. $12-35$ School was the most common source of stress across all points..$\underline{6}$ In depth studies on adverse impact of these type of stressful life events and broadly, detrimental effect of stressful life events in health and disease is necessary with the aim of preventing and managing disorders.

In this study, $16 \%$ of the subjects who were normative adolescent population in Bangladesh had severe level of stress. It can be assumed that this proportion of adolescent population is the risk population group and strong possibility of having psychiatric problems. This rate simulates with the prevalence of psychiatric disorders among children and adolescents. In developed countries, the prevalence of psychiatric disorder among the adole- 
scents is ranged from 11 to $27 \% . \underline{.57-63}$ In developing countries, few studies reported the nearly similar range of prevalence of psychiatric disorder which is 13 to 20\%.64-67 In Bangladesh, prevalence of psychiatric disorder is reported 18\% among 4-6 years old. 68 , 69 As the proportion of severe level of stress in this study among adolescent population is similar to the prevalence rate of psychiatric disorders among adolescents, DSS-Ad has certain predictive value particularly those having severe level of stress score in this scale. Subsequent large scale studies are required to refine the interpretation of DSS-Ad score and its predictive value.

Construction of items of DSS-Ad was based on LER 48 and ALES $\underline{49}$ developed for the assessment of stressors among Indian adolescents. Both the scales are further based on most reputed Homes and Rahi Scale 35 and other scales developed on sound methodology. The item construction was further strengthened by careful analyzing the identified psychosocial stressors in the relevant research in Bangladesh and clinical experience of the researchers. The items were cross checked and finally considered through extensive and in-depth qualitative analyses with the inclusion of culturally prevailing stressful life events among adolescents efficiently and ranked accordingly through quantitative analyses on the basis of response of adolescents in Bangladesh. Therefore, it can be said that the items of this scale are culturally relevant obtained through a sound systemic way.

In the present study, mean stress score for each event was calculated on the summery of the scores of the individual response of the subjects. Individual responses to a life event vary widely and it depends upon several factors including individual coping ability, developmental status, social support systems, relationship and temperament/personality. Therefore, overall summery score of the stressful life events may not reflect the individual's perception. This is one of the drawbacks in majority of the stress scales including this scale and that can be minimized by clustering of the events in many ways and thereby assessed along with considering individual perception.

In this study, on an average an individual adolescent experienced 3.5 number of stressful life events in a year. This finding simulates with the findings of other studies on psychosocial stressors among adolescents. $\underline{49}$ This finding also indicates that adolescents suffer from nearly equal number of stressful life events like adults in Bangladesh reported in a study of developing stress scale for adult population in Bangladesh which was 4 in number for an adult individual.50 In present study, female cases experienced slightly more life events (3.1) than male (2.9). Excess of stressful life events experienced by the girls are reported in several studies. Especially girls in mid to late adolescence report high levels of stress and stress-related symp- toms such as anxiety, depressive symptoms, sleeping difficulties and somatic complaints. $\underline{.70-73}$

This study establishes some psychometric properties of the DSS-Ad. Development of a new scale was driven by the need of an interview-based measure of potentially stress-causing life events in Bangladeshi adolescents, specially meant for the Bangladeshi milieu. Furthermore, it is expected that such an instrument would permit the assessment of antecedent stressors caused due to them and their relationship to psychiatric and physical disorders. In terms of a consistent and reliable measures of stressful life events among adolescents, it was found that this instrument revealed substantially similar internal consistency between two independent and nearly age, sex and socio-economic status matched samples. $\underline{\underline{49}}$ The samples of both studies broadly share general milieu of the Indian Subcontinent.

In this study, face validity of the DSS-Ad was excellent. In assessing content validity of the scale, item level content validity index (I-CVI) was 1 except 6 items and scale level validity index (S-CVI) was 0.93. According to Polit and Beck (2006), $\underline{51}$ the scale will be judged to have excellent content validity if the I-CVI=1 for each item and SCVI $\geq 0.9$. So, the content validity of the DSS-Ad was excellent as both I-CVI and S-CVI were within expected level. In factor analysis of two factor model, no item had salient loading on more than one factor. According to these criteria, each factor obtained in the present study appeared stable. Similar finding was observed by Deacon et al. (2004) $\underline{74}$ where two factor analysis was done. Item 1-10 loaded similarly like this study but communalities were different. For assessing concurrent validity, correlation coefficient was 0.72 between DSS-Ad and ALESS. $\underline{49}$ that was fairly acceptable. For the internal consistency for the DSS-Ad, Cronbach's alpha values were ranging from 0.83-0.97 which was in acceptable range. Therefore, it can be viewed that DSS-Ad has excellent reliability and validity. Subsequent studies are required to strengthen its psychometric properties.

DSS-Ad is the first culturally appropriate, valid and reliable scale in Bangladesh to assess stressful life events among adolescent population developed both in English and Bangla. It is based on sound methodology and provides a straight forward, replicable model for the development of further culturally-validated screening tools for use in Bangladesh and other countries. The stressors of this scale are culturally loaded thus suitable for assessing stressors in Bangladeshi culture.

\section{Conclusion}

This new scale is culturally valid and reliable to measure the stressful life events among Bangladeshi adolescents. This research highlights that academic 
related stressors is one of the key concerned areas of this population in relation to health that needs to be addressed. The scale can be used in identifying potentially risk adolescent population of having disorders.

\section{Ethical Issue}

The ethical clearance was obtained from the Institutional Review Board of the University. Informed consent was taken from the participants of focus group in written format, explaining the research, its purpose and their expected role. The participants were informed that they could leave the group at any point, including after consent has been given.

\section{Conflict of Interest}

Authors declare no conflict of interest.

\section{Acknowledgement}

This research project was supported by a grant from University Grant Commission through Bangabandhu Sheikh Mujib Medical University, Dhaka.

\section{References}

1. Arnett JJ. Adolescent storm and stress, reconsidered. Am Psychol. 1999; 54: 317-26.

2. Larson R, Ham M. Stress and storm and stress in early adolescence-The relationship of negative events with dysphoric affect. Dev Psychol. 1993; 29:130-40.

3. Depue RA, Monroe SM. Conceptualisation and measurement of human disorder and life stress research: The problem of chronic disturbance. Psychol Bull. 1986; 99: 36-51.

4. Brown GW, Harris TO. Life events and illness. New York, Guilford Press, 1989.

5. Colman I, Ataullahjan A. Life course perspectives on the epidemiology of depression. Can J Psychiatry. 2010; 55: 622-32.

6. Madge N, Hawton K, McMahon EM, Corcoran P, De Leo D, De Wilde EJ, Fekete S, Van Heeringen K, Ystgaard M, Arensman E. Psychological characteristics, stressful life events and deliberate selfharm: Findings from child and adolescent selfharm in Europe (CASE) study. Eur Child Adolesc Psychiatry. 2011; 20: 499-508.

7. Tessner KD, Mittal V, Walker EF. Longitudinal study of stressful life events and daily stressors among adolescents at high risk for psychotic disorders. Schizophr Bull. 2011; 37: 432-41.

8. Blazer D, Hughes D, George LK. Stressful life events and the onset of a generalized anxiety syndrome. Am J Psychiatry. 1987; 144: 1178-83.

9. Norman RM, Malla AK. Stressful life events and schizophrenia: A review of the research. Br J Psychiatry. 1993; 162: 161-66.

10. Ingram RE, Luxton DD. Vulnerability and stress model. In: Development of psychopathology: A vulnerability-stress perspective. Hankin BL, John RZ (eds). Chapter 2. California, Sage Publishing, 2005.

11. Steinberg, L. Adolescence. 7th ed. New York, McGraw-Hill, 2005.

12. Low NCP, Dugas E, O'Loughlin E, Rodriguez D, Contreras G, Chaiton M, O'Loughlin J. Common stressful life events and difficulties are associated with mental health symptoms and substance use in young adolescents. BMC Psychiatry. 2012; 12: 116.

13. Grant KE, Compas BE, Thurm AE, McMahon SD, Gipson PY. Stressors and child and adolescent psychopathology: Measurement issues and prospective effects. J Clin Child Adolesc Psychol. 2004; 33: 412-25.

14. Farah M, Nobel K, Hurt H. The developing adolescent brain in socioeconomic context. In: Romer D. (Ed.), Adolescent psychology and the developing brain: Integrating brain and prevention science. New York, Oxford University Press, 2007, pp 37387.

15. Evans GW, Schamberg MA. Childhood poverty, chronic stress, and adult working memory. Proc Natl Acad Sci. 2009; 106: 6545-49.

16. Kiser LJ, Heston J, Millsap PA, Pruitt DB. Physical and sexual abuse in childhood: Relationship with post-traumatic stress disorder. J Am Acad Child Adolsc Psychaitry. 1991; 30: 776-83.

17. Compas BE. Stress and life events during childhood and adolescence. Clin Psychol Rev. 1987; 7: 275-302.

18. Natvig GK, Albrektsen G, Anderssen N, Qvarnstrøm U. School-related stress and psychosomatic symptoms among school adolescents. J Sch Health. 1999; 69: 362-68

19. Murberg TA, Bru E. School-related stress and psychosomatic symptoms among Norwegian adolescents. Sch Psychol Int. 2004; 25: 317-32.

20. Rosmond, R. Role of the pathogenesis of the metabolic syndrome. Psychoneuroendocrinology 2005; 30: $1-10$.

21. Oren E, Gerald L, Stern DA, Martinez FD, Wright AL. Self-reported stressful life events during adolescence and subsequent asthma: A longitudinal study. J Allergy Clin Immunol Pract. 2017; 5: 42734.

22. Gershoff ET, Aber JL, Raver DC. Child poverty in the US: An evidence-based conceptual framework for programs and policies. In: Lerner RM, Jacobs F, Wertlieb D (eds.). Handbook of applied develop- 
mental science. Vol. 2. USA, Sage Publications, 2003, pp 81-136.

23. Thoresen CE, Eagleston JR. Chronic stress in children and adolescents. Theory Pract. 1983; 22: 48-56.

24. Agid O, Kohn Y, Lerer B. Environmental stress and psychiatric illness. Biomed Pharmacother. 2000; 54: 135-41.

25. Mullick MSI. Psychosocial stressors in deliberate self harm. Bangladesh Med J. 1992; 21: 79-83.

26. Mullick MSI. Somatoform disorders in children and adolescents. Bangladesh Med Res Counc Bull. 2002; 28: 112-22.

27. Das A, Mullick MSI, Algin S, Quasar MMAS, Shah MA. Presentation of somatic symptoms and associated abnormal psychosocial situations among children and adolescents. Bangladesh J Psychiatry. 2012; 26: 46-53.

28. Mullick MSI. Children and adolescents presenting with school refusal: A clinical study. Bangladesh J Child Health. 2003; 27: 14-18.

29. Khanam M, Mullick MSI, Nahar JS, Salam MA. Conversion disorder in children and adolescents: A clinical study. Bangladesh J Psychiatry. 2002; 2631.

30. Ahsan MS, Mullick MSI, Sobhan MA, Khanam M, Nahar JS, Salam MA, Ali R, Islam M, Kabir MS. Subtypes of dissociative (conversion) disorder in two hospitals in Bangladesh. Mymensingh Med J. 2010; 19: 66-71.

31. Roy S, Roy GT, Begum M, Karim ME, Akhter MS, Begum O. Psycho-social stressors and life events of the patients with conversion disorder: A study in a tertiary care hospital in north east zone of Bangladesh. Bangladesh J Psychiatry. 2014; 28: 4144.

32. Mullick MSI, Nahar JS, Chowdhury NF, Rahman W, Islam MM, Qusar MMAS, Rahman MM, Shahidullah M. Psychiatric disorder among children of 5 to 18 years old of 'SIDR' cyclone affected areas. Bangabandhu Sheikh Mujib Med Univ J. 2014; 7: 2026.

33. Mullick MSI, Algin S, Ahmed HU, Majumder AH. Marriage and other psychological stressors in the causation of psychiatric disorder. Bangabandhu Sheikh Mujib Med Univ J. 2016; 9: 129-34.

34. Mullick MSI, Nahar JS, Haq SA. Psychiatric morbidity, stressors, impact, and burden in juvenile idiopathic arthritis. J Health Popul Nutr. 2005; 23: $142-49$.

35. Holmes TH, Rahe RH. The social readjustment rating scale. J Psychosom Res. 1967; 11: 213-18.

36. Singh G, Kaur D, Kaur H. Presumptive stressful life events scale (PSLES): A new stressful life events scale for use in India. Indian J Psychiatry. 1984; 26: 107-14.

37. Monaghan JH, Robinson JO, Dodge JA. The
Children's Life Events inventory. J Psychosom Res. 1979; 23: 63-68.

38. Newcomb MD, Huba GJ, Bentler PM. A multidimensional assessment of stressful life events among adolescents: Derivation and correlates. J Health Social Behav. 1981; 22: 400-15.

39. Swearingen EM, Cohen LH. Measurement of adolescents' life events: The junior high school life experiences survey. Am J Community Psychol. 1985; 13: 69-85.

40. Yeaworth RC, York J, Hussey MA, Ingle Me, Goodwin $\mathrm{T}$. The development of an adolescent life change event scale. Adolescence 1980; 15: 91-97.

41. Compas BE, Davis GE, Forsythe CJ, Wagner BM. Assessment of major and daily stressful events during adolescence: The adolescent perceived events scale. J Consult Clin Psychol. 1987; 55: 53441.

42. Byrne DG, Davenport SC, Mazanov J. Profiles of adolescent stress: The development of the adolescent stress questionnaire (ASQ). J Adolesc. 2007; 30: 393-416.

43. De Meuse KP. The relationship between life events and indices of class room performance. Teaching Psychol. 1985; 12: 146-49.

44. Anniko MK, Boersma K, van Wijk NPL, Byrne D, Tillfors M. Development of a shortened version of the adolescent stress questionnaire (ASQ-S): Construct validity and sex invariance in a large sample of Swedish adolescents. Scandinavian J Child Adolesc Psychiatry Psychol. 2018; 6: 4-15.

45. Dohrenwend BS, Askenasy AR, Krasnoff L, Dohrenwend BP. Exemplification of a method for scaling life events: The peri life events scale. J Health Social Behav. 1978; 19: 205-29.

46. González de Rivera JL y Revuelta, Fumero AM. The assessment of vital events: Spanish adaptation of the Holmes and Rahe scale. Psiquis 1983; 4: 7-11.

47. Green BL, Chung JY, Daroowalla A, Kaltman S, Debenedictis C. Evaluating the cultural validity of the stressful life events screening questionnaire.Violence Against Women. 12: 1191-213.

48. Coddington RD. The significance of life events as etiologic factors in diseases of children: A survey of professionals. J Psychosom Res. 1972; 16: 205-13.

49. Aggarwal S, Prabhu CH, Anand LC, Kotwal LC. Stressful life events among adolescents: The development of a new measure. Indian J Psychiatry. 2007; 49: 96-102.

50. Mullick MSI, Algin S, Islam M, Phillipson A, Nahar JS, Morshed NM, Chowdhury HR, Shahid SFB. Dhaka stress scale- Adult: A scale for assessing psychosocial stressors among adults. Bangabandhu Sheikh Mujib Med Univ J. 2019; 12: 119-27.

51. Beaton DE, Bombardier C, Guillemin F, Ferraz MB. Guidelines for the process of cross-cultural adapta- 
tion of self-report measures. Spine 2000; 25: 318691.

52. Polit DF, Beck CT. The content validity index: Are you sure you know what's being reported? Critique and recommendation. Res Nurs Health. 2006; 29: 489-97.

53. Drost EA. Validity and reliability in social science research. Education Res. 2011; 38: 105-23.

54. Peacock JL, Peacock PJ. Oxford handbook of medical statistics. $1^{\text {st }}$ ed. Oxford, Oxford University Press, 2011.

55. Sadana R, D'Souza C, Hyder AA, Chowdhury AM. Importance of health research in South Asia. BMJ. 2004: 328 ; 826-30

56. Anniko MK, Boersma K, Tillfors M. Sources of stress and worry in the development of stressrelated mental health problems: A longitudinal investigation from early- to mid-adolescence. Anxiety Stress Coping. 2009: 32: 155-67.

57. Costello EJ, Mustillo S, Erkanli A, keeler G, Angold A. Prevalence and development of psychiatric disorder in childhood and adolescence. Arch Gen Psychiatry. 2003; 60: 837-44.

58. Anderson JC, Williams S, McGee R, Silva PA. DSMIII disorders in preadolescent children. Arch Gen Psychiatry. 1987; 44: 69-76.

59. Kashani JH, Orvaschel H, Rosenberg TK, Reid JC. Psychopathology in a community sample of children and adolescents: A development perspective. J Am Acad Child Adolesc Psychiatry. 1989; 28: 70106.

60. Meltzer H, Gatward R, Goodman R, Ford T. Mental health of children and adolescents in Great Britain. London, The Stationary Office, 2000.

61. Shaffer D, Fisher P, Dulcan MK, Davies M, Piacentini J, Schwab-Stone ME, Lahey BB, Bourdon K, Jensen PS, Bird HR, Canino G, Regier DA. The NIMH diagnostic interview schedule for children version 2.3 (DISC-2-3): Description, acceptability, prevalence rates, and performance in the MECA study. J Am Acad Child Adolesc Psychiatry. 1996; 35: 865-77.

62. Velez CN, Johnson J, Cohen P. A longitudinal analysis of selected risk factors for childhood psychopathology. J Am Acad Child Adolesc Psychiatry. 1989; 28: 861-65.

63. Verhulst FC, van der Ende J, Ferdinand RF, Kasius MC. The prevalence of DSM-III-R diagnoses in a national sample of Dutch adolescents. Arch Gen Psychiatry. 1997; 54: 329-36.
64. Balgir RS, Sidhu BS, Garg M, Wats A, Sohal S. Distribution of psychiatric morbidity among school going adolescents in a district of North India. Int J Med Res Health Sci. 2016; 5: 1-9.

65. Bird HR, Canino G, Rubio-Stipec M, Gould MS, Ribera J, Sesman M, Woodbury M, HuertasGoldman S, Pagan A, Sanchez-Lacay A, Moscoso $\mathrm{M}$. Estimates of the prevalence of childhood maladjustment in a community survey in Puerto Rico. Arch Gen Psychiatry. 1988; 45: 1120-26.

66. Fleitlich-Bilyk B, Goodman R. The prevalence of child psychiatric disorders in Southeast Brazil. J Am Acad Child Adolesc Psychiatry. 2004; 43: 72734.

67. Xiaoli $Y$, Chao J, Wen P, Wenming X, Fang L, Ning L, Huijuan M, Jun N, Ming L, Xiaoxia A, Chuanyou Y, Zenguo F, Lili L, Lianzheng Y, Lijuan T, Guowei $\mathrm{P}$. Prevalence of psychiatric disorder among children and adolescents in Northeast China. PLoS One. 2014; 9: e111223.

68. Mullick MS, Goodman R. Questionnaire screening for mental health problems in Bangladeshi children: A preliminary study. Soc Psychiatry Psychiatr Epidemiol. 2001; 36: 94-99.

69. Rabbani MG, Alam MF, Ahmed HU, Sarkar M, Islam MS, Anwar N, Zaman MM, Chowdhury S, Chowdhury MWA, Das SK, Hamid MA, Islam MT, Mohir MA, Jahan NA, Rahman AHM, Choudhury S, Chowdhury KP, Wahab MA, Rahman F, Mandal MC, Hossain MD, Bhowmik AD, Bashar MK, Khan NM, Uddin MJ, Khan MJR. Prevalence of mental disorders, mental retardation, epilepsy and substance abuse in children. Bangladesh J Psychiatry. 2009; 23: 11-52.

70. Sheha A, Walsh C, MacMillan H, Steiner M. Child maltreatment and HPA axis dysregulation: Relationship to major depressive disorder and post traumatic stress disorder in females. Psychoneuroendocrinology 2005; 30: 162-78.

71. MacLean A, Sweeting H, Egan M, Der G, Adamson $J$, Hunt K. How robust is the evidence of an emerging or increasing female excess in physical morbidity between childhood and adolescence? Results of a systematic literature review and metaanalyses. Soc Sci Med. 2013; 78: 96-112.

72. Ravens-Sieberer U, Torsheim T, Hetland J, Vollebergh W, Cavallo F, Jericek H, Erhart M. Subjective health, symptom load and quality of life of children and adolescents in Europe. Int J Public Health. 2009; 54: 151-59.

73. Sweeting H, Young R, West P. GHQ increases among Scottish 15 year olds 1987-2006. Soc Psychiatry Psychiatr Epidemiol. 2009; 44: 579-86. 